\title{
PHYSICAL ACTIVITY RISK BEHAVIOUR IN SCHOOL-AGED CHILDREN IS ASSOCIATED WITH OVERWEIGHT AND MATERNAL CHARACTERISTICS
}

\author{
Sanja Musić Milanović1,2, Helena Križan', Laura Pavičić \\ Maja Lang Morović ${ }^{1}$, and Mario Baić ${ }^{3}$ \\ ${ }^{1}$ Health Promotion Division, Croatian Institute of Public Health, Zagreb, Croatia \\ ${ }^{2}$ School of Public Health Andrija Štampar, School of Medicine, University of Zagreb, \\ Zagreb, Croatia \\ ${ }^{3}$ Faculty of Kinesiology, University of Zagreb, Zagreb, Croatia
}

Original scientific paper

DOI $10.26582 / \mathrm{k} .53 .2 .14$

\begin{abstract}
:
Given the importance of physical activity for the prevention of overweight, this study sought to determine the type and number of physical activity risk behaviours that were associated with overweight in Croatian school children and their association with maternal characteristics - mothers' formal education, employment, and weight status. This paper used data from the Croatian Childhood Obesity Surveillance Initiative study from 2015/2016. During an eight-week period, anthropometric measurements of children were taken. Data on children's physical activity risk behaviours and their mothers' characteristics were provided by the mothers of 4,045 children from the second and third grade (median age 8.6 years) who were included in the analysis. Insufficient active play outdoors, excessive screen time and exhibiting two or three physical activity risk behaviours were significantly associated with childhood overweight. Children of less educated mothers had lower odds for insufficient active play outdoor and higher odds for insufficient frequenting of a sports or dancing club and exhibiting one, two or three physical activity risk behaviours. Children of mothers who were overweight had higher odds for insufficient sleeping, insufficient frequenting of a sports or dancing club and exhibiting two risk behaviours. Children of unemployed mothers had higher odds for insufficient frequenting of a sports or dancing club and for exhibiting two or three risk behaviours. Physical activity risk behaviours in school children were associated with overweight, as well as their mothers' characteristics. This finding should be taken into consideration when planning and implementing health promotion and childhood overweight prevention activities.
\end{abstract}

Key words: sport, formal education, employment, weight status, risk behaviours, children

\section{Introduction}

According to a recent publication from the World Health Organization Regional Office for Europe (WHO/Europe), the rates of childhood overweight and obesity in some countries of the European region of WHO are as high as 40\% (WHO, 2018). Physical activity (PA) is recognized as an important factor in prevention of childhood overweight and obesity as well as in retention of adulthood obesity development (Ariza, et al., 2019). There is strong evidence that higher amounts of PA are associated with a reduced risk of excessive increases in bodyweight and adiposity and with normal growth rates in children aged three to 17 years (Ekelund, Hildebrand, \& Collings, 2014; Guinhouya, Samouda, Zitouni, Vilhelm, \& Hubert, 2011; U.S. Department ..., 2018). Nevertheless, the situation regarding the PA of children and youth is a concern worldwide since many children still do not meet the minimal recommended levels of 60 minutes of moderate to vigorous-intensity PA (MVPA) per day (Aubert, et al., 2018; Mendis, et al., 2014; WHO, 2020).

Active transportation going to and from school (cycling or walking), active play (unstructured, outdoor PA in children's free time) and participation in sports or dancing clubs are considered to be major contributors to total PA among children (Whiting, et al., 2020), so the absence of these behaviours could be considered as a risk factor. Previous studies have mostly looked at children's weight status in relation to a global measure of PA and there is a scarcity of research on the specific types of PA and their association with childhood weight 
status (Gunnarsdottir, Rogers, Jakicic, \& Hill, 2014; Masoumi, 2017). Specific sedentary behaviours such as TV-viewing may also be associated with childhood overweight independent of PA but there is also no consensus on this since these results may be explained by residual confounding (Ekelund, et al., 2014). Short sleep duration, according to existing evidence, can result in metabolic changes that contribute to the development of obesity, as well (Taheri, 2006), which is why recently more and more studies and guidelines focus on the combined effects of time spent in PA, sedentary behaviours and sleep (Chastin, Palarea-Albaladejo, Dontje, \& Skelton, 2015; Tremblay, et al., 2016). An integrated view of all movement behaviours is necessary, since these behaviours, apart from their independent association with childhood weight status, are also in constant interaction. One example of this is a negative loop in which a sedentary lifestyle with low levels of PA leads to low motor skills, and the low perceptions of motor competence then further predict physical inactivity, poor fitness and obesity (Stodden, et al., 2008).

Parents exert an important influence on their child's PA behaviour (Welk, Wood, \& Morss, 2003). Specifically, mother's work arrangements have been found to be strongly associated with children's and adolescents' sedentary behaviour (Brown, Broom, Nicholson, \& Bittman, 2010; Martin, Lippert, Chandler, \& Lemmon, 2018). One British study found that children whose mothers were employed were more likely to use the television/computer at least two hours daily or be driven to school than children whose mothers had never been employed (Sherburne Hawkins, et al., 2009). A recent pooled analysis also showed that children whose mothers reported a higher level of education had lower levels of objectively measured PA and spent more time sedentary (Sherar, et al., 2016). A systematic review encompassing 150 studies mainly from North American, European, and a few Oceanian countries found that maternal education was positively correlated with PA among adolescents (12-18 years) but not children (3-12 years) (Ferreira, et al., 2007). Although few studies investigated the correlation of maternal weight status and children's movement behaviours, there is some evidence indicating that maternal overweight is linked to more sedentary time in children (Pahkala, et al., 2010; Péneau, Salanave, Rolland-Cachera, Hercberg, \& Castetbon, 2011). Given the importance of PA for prevention of overweight, this study sought to determine the type and number of PA risk behaviours that were associated with overweight in Croatian school children. The study also sought to examine the association between the presence of PA risk behaviours and maternal characteristics - mothers' formal education, employment and weight status.

\section{Methods}

The Childhood Obesity Surveillance Initiative (COSI) was established by WHO/Europe in 2007 with the aim of collecting data on children's body weight, height, and hip and waist circumference in order to make this data comparable among children aged 6.0-9.9 years in European countries (Musić Milanović, Lang Morović, \& Markelić, 2018). This paper was based on the Croatian COSI study from 2015/2016.

\section{Sample}

The sampling was conducted at a national level and in accordance with the standardized COSI Protocol (WHO, 2016). So 182 second grade classes from 164 elementary schools were randomly selected using the STATISTICA program and paired with third grade classes from the same school. Overall, out of 7,150 children invited to participate, 5,662 children (79.2\%), aged 6.33 to 11.08 years, participated in the study. After selecting only children that had Family Forms filled in by their mothers (and not other family members) and children that had no missing values on any of the investigated variables, the final sample size was 4,045 .

\section{Data collection}

During an eight-week period in 2015, trained investigators have acquired anthropometric measurements of children. Measuring was performed in schools, in gym halls or classrooms. Children were measured using standardized anthropometric instruments: a weight scale (SECA 877) measuring body weight to the nearest $0.1 \mathrm{~kg}$ and a stadiometer (SECA 217) measuring body height to the nearest $0.1 \mathrm{~cm}$. Additional socioeconomic and lifestyle data were gathered using the standardized COSI Family Form. The Form was filled in by the child's parents or caregivers. A detailed description of the data collection procedures was given elsewhere (Musić Milanović, et al., 2018).

\section{Variables}

Studied variables included children's anthropometric measures as well as data on children's PA risk behaviours and mothers' characteristics. The child's geographical region was determined according to his/her place of residence and classified according to the NUTS classification (European Union, 2015), with the City of Zagreb considered as a separate category because of its cultural and sociodemographic specificities.

Body mass index (BMI) for each child and mother was calculated as weight in kilograms divided by height in square metres. In this study, overweight was defined by and presented using the set of cut-off points published by WHO (WHO, 2013). 
For the purpose of this paper a PA risk score was created for each child, based on a study published by Wijnhoven et al. (2015). The following PA risk behaviours were considered: using inactive transportation going to and from school, actively playing outside $<$ one h/day, screen time $\geq$ two h/day, sleep duration $<$ nine $\mathrm{h} /$ day and going to a sports or dancing club $<$ two $\mathrm{h} /$ week. Questions and answers categories, on which the presence of risk behaviour was determined, were described elsewhere (Wijnhoven, et al., 2015). To calculate the score, one point was assigned to the presence of each PA risk behaviour (zero otherwise) and subsequently all points were added together.

The following maternal characteristics were analysed:

- Maternal education - three categories: 1) elementary school or less; 2) high school; 3) undergraduate degree or higher

- Maternal employment status - two categories: 1) employed; 2) unemployed. Mothers were classified as employed if they were government employed, non-government employed or self-employed. They were classified as unemployed if they were unemployed, able to work, unemployed, unable to work, student, homemaker or retired.

- Maternal overweight - two categories: 1) not overweight; 2) overweight. As part of the Family Form mothers gave information on their weight and height. If the calculated BMI was greater than or equal to 25 , mothers were classified as overweight; if it was under 25 , mothers were classified as not overweight.

\section{Ethical issues}

COSI research in Croatia was approved by the Ethics Committee of the Croatian Institute of Public Health (Class: 602-01/15-01/0242) in July 2015. Parents were fully informed about all study procedures, and their written informed consent was obtained for taking measurements of children. Additionally, immediately before the measuring, children were also asked if they were willing to participate in the research.

\section{Statistical analysis}

All statistical analyses were performed using the statistical package SPSS Statistics 21.0 (IBM Corporation, Chicago, IL, USA). The level of significance was set at $\mathrm{p}<.05$. Post-stratification weights to adjust for the sampling design, oversampling and nonresponse were used in all analyses to infer the results from the sample to the population.

The sample was analysed descriptively using medians, interquartile range and frequencies where appropriate.
Adjusted odds ratios (AdjORs) and 95\% confidence intervals (CIs) of being overweight (compared to not being overweight) related to PA risk behaviours and $P A$ risk score were estimated through logistic regression analyses. All five PA risk behaviours were modelled in the same model. AdjORs and $95 \%$ CIs of exhibiting a PA risk behaviour (compared to not exhibiting one) and having a certain $P$ A risk score (compared to having a score of zero) related to maternal characteristics were estimated through logistic regression analyses. Results for having five PA risk behaviours were not shown because of a too small number of observations to calculate odds ratios. All models included child's age and geographical region among covariates. All models were performed on the overall sample and stratified by sex, with sex included as a covariate in models on the overall sample.

\section{RESULTS}

\section{Descriptive characteristics of the sample}

A description of the study sample, according to the investigated variables, is shown in Table 1.

When looking at the number of PA risk behaviours present in a single child, it was determined that most children, $39.4 \%$ of them, had one risk behaviour. Two risk behaviours could be found in $29.5 \%$ and three risk behaviours in $9.9 \%$ of the studied children. A very small share of children had four or all five risk behaviours, 0.9 and $0.0 \%$, respectively. According to their mothers, around one fifth of children, $20.3 \%$, exhibited none of the observed risk behaviours.

\section{Association of physical activity behaviours and childhood overweight}

Results of a binary logistic regression (Table 2) showed that actively playing outside for less than one hour per day and spending more than two hours per day in front of the screen were significantly associated with childhood overweight. When stratified by sex, these two associations remained significant for both boys and girls, with the highest odds ratio observed, 1.63, being for boys who insufficiently actively play outside.

\section{Association of maternal characteristics and physical activity behaviours}

Maternal education was significantly associated with actively playing outside for less than one hour a day and going to a sports or dancing club for less than two hours a week. Children of less educated mothers had lower odds for insufficiently active playing outside and higher odds for not going to a sports or dancing club regularly in comparison to 
Table 1. Descriptive analysis of investigated variables. Childhood Obesity Surveillance Initiative 2015-2016, Croatia

\begin{tabular}{|c|c|c|c|}
\hline \multicolumn{2}{|l|}{ Age (years) } & \multicolumn{2}{|l|}{ Physical activity risk behaviours (\%) } \\
\hline Median & 8.6 & Using inactive transportation going to and from school & 30.0 \\
\hline Q1 -Q3 & $8.1-9.2$ & Actively playing outside $<1 \mathrm{~h} / \mathrm{d}$ & 8.3 \\
\hline Gender (\%) & & Screen time $\geq 2 \mathrm{~h} / \mathrm{d}$ & 52.4 \\
\hline Boys & 50.6 & Sleep duration $<9 \mathrm{~h} / \mathrm{d}$ & 5.9 \\
\hline Girls & 49.4 & Going to a sports or dancing club $<2 \mathrm{~h} /$ week & 35.1 \\
\hline Geographical region (\%) & & Maternal education level (\%) & \\
\hline Continental & 50.2 & Elementary school & 6.6 \\
\hline Adriatic & 32.4 & High school & 60.7 \\
\hline City of Zagreb & 17.4 & Undergraduate degree or higher & 32.7 \\
\hline Nutritional status (\%) & & Maternal employment status (\%) & \\
\hline Underweight & 0.8 & Employed & 76.4 \\
\hline Normal weight & 62.5 & Unemployed & 23.6 \\
\hline Overweight & 21.7 & Maternal overweight status (\%) & \\
\hline \multirow[t]{2}{*}{ Obese } & 15.1 & Overweight & 30.2 \\
\hline & & Not overweight & 69.8 \\
\hline
\end{tabular}

Note. Q1 - first quartile; Q3 - third quartile

Table 2. Adjusted odds ratios (adjORs) and 95\% confidence intervals (CIs) of being overweight (compared to not being overweight) related to physical activity risk behaviours and the physical activity risk behaviour score

\begin{tabular}{|c|c|c|c|c|c|c|c|c|c|}
\hline & \multicolumn{5}{|c|}{$\begin{array}{l}\text { Physical activity risk behaviours } \\
\text { (reference }=\text { no risk) } \\
\text { - adjOR }[95 \% \mathrm{Cl}]\end{array}$} & \multicolumn{4}{|c|}{$\begin{array}{c}\text { Physical activity risk behaviour score } \\
\text { (reference }=0) \\
\text { - adjOR }[95 \% \mathrm{Cl}]\end{array}$} \\
\hline & $\begin{array}{l}\text { Using inactive } \\
\text { transportation } \\
\text { going to and } \\
\text { from school }\end{array}$ & $\begin{array}{l}\text { Actively } \\
\text { playing } \\
\text { outside } \\
<1 \mathrm{~h} / \mathrm{d}\end{array}$ & $\begin{array}{l}\text { Screen } \\
\text { time } \geq 2 \\
\text { h/d }\end{array}$ & $\begin{array}{l}\text { Sleep } \\
\text { duration } \\
<9 \mathrm{~h} / \mathrm{d}\end{array}$ & $\begin{array}{l}\text { Going to a } \\
\text { sports or } \\
\text { dancing } \\
\text { club }<2 \mathrm{~h} / \\
\text { week }\end{array}$ & 1 & 2 & 3 & 4 \\
\hline Overall & $\begin{array}{c}1.08 \\
{[0.94-1.25]}\end{array}$ & $\begin{array}{c}1.50 \\
{[1.20-1.88]}\end{array}$ & $\begin{array}{c}1.23 \\
{[1.08-1.40]}\end{array}$ & $\begin{array}{c}0.98 \\
{[0.74-1.29]}\end{array}$ & $\begin{array}{c}1.01 \\
{[0.88-1.15]}\end{array}$ & $\begin{array}{c}1.02 \\
{[0.86-1.22]}\end{array}$ & $\begin{array}{c}1.23 \\
{[1.02-1.49]}\end{array}$ & $\begin{array}{c}1.57 \\
{[1.23-2.01]}\end{array}$ & $\begin{array}{c}0.75 \\
{[0.35-1.58]}\end{array}$ \\
\hline Boys & $\begin{array}{c}1.10 \\
{[0.91-1.34]}\end{array}$ & $\begin{array}{c}1.63 \\
{[1.16-2.28]}\end{array}$ & $\begin{array}{c}1.20 \\
{[1.00-1.44]}\end{array}$ & $\begin{array}{c}0.92 \\
{[0.63-1.35]}\end{array}$ & $\begin{array}{c}1.11 \\
{[0.91-1.34]}\end{array}$ & $\begin{array}{c}1.01 \\
{[0.80-1.28]}\end{array}$ & $\begin{array}{c}1.24 \\
{[0.96-1.60]}\end{array}$ & $\begin{array}{c}1.75 \\
{[1.24-2.48]}\end{array}$ & $\begin{array}{c}0.72 \\
{[0.21-2.44]}\end{array}$ \\
\hline Girls & $\begin{array}{c}1.07 \\
{[0.87-1.31]}\end{array}$ & $\begin{array}{c}1.41 \\
{[1.03-1.92]}\end{array}$ & $\begin{array}{c}1.27 \\
{[1.05-1.54]}\end{array}$ & $\begin{array}{c}1.07 \\
{[0.72-1.59]}\end{array}$ & $\begin{array}{c}0.92 \\
{[0.76-1.11]}\end{array}$ & $\begin{array}{c}1.04 \\
{[0.79-1.36]}\end{array}$ & $\begin{array}{c}1.23 \\
{[0.93-1.62]}\end{array}$ & $\begin{array}{c}1.44 \\
{[1.01-2.05]}\end{array}$ & $\begin{array}{c}0.78 \\
{[0.30-2.02]}\end{array}$ \\
\hline
\end{tabular}

Note. AdjORs and $95 \% \mathrm{Cl}$ were estimated using binary logistic regression analyses. Score categories were defined as the number of physical activity risk behaviours. Results for having five risk behaviours were not shown because of a too small number of observations to calculate odds ratios. Besides physical activity risk behaviours or the physical activity risk behaviour score, all models included child's age and geographical region among covariates. Overall model included sex as well.

children of mothers with an undergraduate degree or higher. When stratified by sex, the same pattern could be applied to each group except for the girls whose mothers finished elementary school; they did not have significantly lower odds for insufficient active play outside. Children of mothers who were overweight had $46 \%$ higher odds for sleeping under nine hours and $22 \%$ higher odds for going to a sports or dancing club for less than two hours a week. Maternal overweight was not found to be significantly associated with any PA risk behaviour among girls, and among boys it was only associated with not going to a sports or dancing club regularly.

Children of unemployed mothers had higher odds for going to a sports or dancing club for less than two hours a week, both overall and stratified by sex (Table 3 ).

As seen in Table 2, children with two and three PA risk behaviours had significantly higher odds for overweight, 1.23 and 1.57 times, respectively, in comparison to those who exhibited zero behaviours. When stratified by sex, only boys and girls 
Table 3. Adjusted odds ratios (adjORs) and 95\% confidence intervals (CIs) of exhibiting a physical activity risk behaviour (compared to not exhibiting one) related to maternal education, maternal employment status and maternal overweight

\begin{tabular}{|c|c|c|c|c|}
\hline & \multicolumn{2}{|c|}{$\begin{array}{c}\text { Maternal education } \\
\text { (reference=undergraduate degree or higher) }\end{array}$} & \multirow{2}{*}{$\begin{array}{c}\text { Maternal overweight } \\
\text { (reference=not } \\
\text { overweight) }\end{array}$} & \multirow{2}{*}{$\begin{array}{c}\text { Maternal employment } \\
\text { (reference=employed) }\end{array}$} \\
\hline & Elementary school & High school & & \\
\hline \multicolumn{5}{|c|}{ Using inactive transportation going to and from school - adjOR $[95 \% \mathrm{Cl}]$} \\
\hline Overall & $0.91[0.67-1.25]$ & $1.03[0.88-1.20]$ & $0.98[0.85-1.14]$ & $1.12[0.95-1.32]$ \\
\hline Boys & $0.82[0.53-1.26]$ & $1.05[0.85-1.30]$ & $0.93[0.75-1.14]$ & $1.10[0.87-1.39]$ \\
\hline Girls & $1.05[0.66-1.65]$ & $1.01[0.81-1.25]$ & $1.04[0.84-1.29]$ & $1.14[0.89-1.45]$ \\
\hline \multicolumn{5}{|c|}{ Actively playing outside $<1 \mathrm{~h} / \mathrm{d}-$ adjOR $[95 \% \mathrm{Cl}]$} \\
\hline Overall & $0.41[0.23-0.72]$ & $0.44[0.35-0.56]$ & $1.02[0.80-1.32]$ & $0.96[0.71-1.31]$ \\
\hline Boys & $0.33[0.14-0.78]$ & $0.40[0.28-0.58]$ & $0.97[0.66-1.41]$ & $0.97[0.62-1.54]$ \\
\hline Girls & $0.48[0.22-1.03]$ & $0.46[0.34-0.64]$ & $1.07[0.76-1.50]$ & $0.96[0.63-1.45]$ \\
\hline \multicolumn{5}{|c|}{ Screen time $\geq 2 \mathrm{~h} / \mathrm{d}-$ adjOR $[95 \% \mathrm{Cl}]$} \\
\hline Overall & $1.07[0.80-1.42]$ & $1.06[0.93-1.22]$ & $1.12[0.98-1.29]$ & $1.07[0.92-1.25]$ \\
\hline Boys & $1.08[0.73-1.59]$ & $0.98[0.81-1.20]$ & $1.18[0.97-1.43]$ & $1.06[0.86-1.32]$ \\
\hline Girls & $1.03[0.67-1.57]$ & $1.15[0.95-1.41]$ & $1.06[0.87-1.28]$ & $1.09[0.87-1.36]$ \\
\hline \multicolumn{5}{|c|}{ Sleep duration $<9 \mathrm{~h} / \mathrm{d}-\operatorname{adjOR}[95 \% \mathrm{Cl}]$} \\
\hline Overall & $0.79[0.42-1.47]$ & $0.86[0.65-1.15]$ & $1.46[1.10-1.92]$ & $0.81[0.57-1.14]$ \\
\hline Boys & $1.03[0.48-2.20]$ & $0.88[0.58-1.33]$ & $1.43[0.98-2.11]$ & $0.98[0.62-1.56]$ \\
\hline Girls & $0.43[0.13-1.46]$ & $0.85[0.57-1.27]$ & $1.49[1.00-2.22]$ & $0.64[0.37-1.10]$ \\
\hline \multicolumn{5}{|c|}{ Going to a sports or dancing club $<2 \mathrm{~h} /$ week - adjOR $[95 \% \mathrm{Cl}]$} \\
\hline Overall & $5.38[3.98-7.28]$ & $2.28[1.94-2.68]$ & $1.22[1.06-1.41]$ & $1.47[1.26-1.73]$ \\
\hline Boys & $3.95[2.63-5.93]$ & 2.29 [1.80-2.91] & $1.40[1.14-1.72]$ & $1.49[1.18-1.86]$ \\
\hline Girls & $8.67[5.29-14.22]$ & $2.28[1.83-2.84]$ & $1.08[0.88-1.32]$ & $1.47[1.17-1.85]$ \\
\hline
\end{tabular}

Note. AdjORs and $95 \% \mathrm{Cls}$ were estimated using a binary logistic regression analysis. Besides maternal characteristics, all models included child's age and geographical region among covariates. Overall models included sex as well.

Table 4. Adjusted odds ratios (adjORs) and 95\% confidence intervals (CIs) of having a certain physical activity risk behaviour score (compared to having a score of zero) related to maternal education, employment status and maternal overweight

\begin{tabular}{rlcccc}
\hline \multirow{2}{*}{ Score } & & \multicolumn{2}{c}{$\begin{array}{c}\text { Maternal education } \\
\text { (reference= undergraduate degree } \\
\text { or higher) }\end{array}$} & $\begin{array}{c}\text { Maternal overweight } \\
\text { (reference=not } \\
\text { overweight) }\end{array}$ & $\begin{array}{c}\text { Maternal employment } \\
\text { status } \\
\text { (reference= employed) }\end{array}$ \\
\cline { 3 - 6 } & & Elementary school & High school & Overweight & Unemployed \\
\hline \multirow{3}{*}{$\mathbf{1}$} & Overall & $1.85[1.17-2.91]$ & $1.34[1.11-1.61]$ & $1.09[0.90-1.33]$ & $1.14[0.91-1.43]$ \\
& Boys & $1.44[0.82-2.51]$ & $1.24[0.97-1.60]$ & $1.15[0.88-1.49]$ & $1.28[0.94-1.73]$ \\
& Girls & $2.99[1.31-6.80]$ & $1.47[1.12-1.91]$ & $1.04[0.78-1.38]$ & $1.00[0.71-1.41]$ \\
\hline \multirow{2}{*}{$\mathbf{2}$} & Overall & $2.28[1.44-3.62]$ & $1.39[1.14-1.69]$ & $1.36[1.11-1.66]$ & $1.41[1.12-1.78]$ \\
& Boys & $1.59[0.89-2.83]$ & $1.17[0.90-1.54]$ & $1.34[1.02-1.77]$ & $1.45[1.06-2.00]$ \\
& Girls & $4.17[1.83-9.50]$ & $1.66[1.24-2.21]$ & $1.35[1.01-1.82]$ & $1.35[0.95-1.90]$ \\
\hline \multirow{3}{*}{3} & Overall & $3.59[2.07-6.24]$ & $1.67[1.26-2.21]$ & $1.24[0.95-1.62]$ & $1.41[1.04-1.90]$ \\
& Boys & $2.39[1.13-5.04]$ & $1.65[1.10-2.50]$ & $1.38[0.95-2.01]$ & $1.55[1.02-2.36]$ \\
& Girls & $6.71[2.70-16.67]$ & $1.73[1.17-2.54]$ & $1.11[0.76-1.62]$ & $1.27[0.82-1.96]$ \\
\hline \multirow{2}{*}{$\mathbf{4}$} & Overall & $0.62[0.09-4.34]$ & $0.89[0.43-1.85]$ & $1.54[0.76-3.12]$ & $1.73[0.77-3.86]$ \\
& Boys & $0.98[0.11-8.88]$ & $0.63[0.18-2.21]$ & $2.97[0.94-9.34]$ & $1.51[0.37-6.09]$ \\
& Girls & $*$ & $1.12[0.45-2.76]$ & $1.00[0.39-2.59]$ & $1.83[0.68-4.94]$ \\
\hline
\end{tabular}

Note. ${ }^{*}$ - A too small number of observations to calculate odds ratios.

Score categories were defined as the number of physical activity risk behaviours. AdjORs and $95 \%$ Cls were estimated using a multinomial logistic regression analysis. Besides maternal characteristics, all models included child's age and geographical region among covariates. Overall model included sex as well. Results for having five risk behaviours were not shown because of a too small number of observations to calculate odds ratios. 
with three risk behaviours had higher odds for overweight.

Overall, as seen in Table 4, lower maternal education was significantly associated with exhibiting one, two or three PA risk behaviours. The same result was found among girls, but among boys lower maternal education was only associated with exhibiting three risk behaviours.

Children of overweight mothers had significantly higher odds for exhibiting two risk behaviours with the same result found among boys and girls separately as well.

Children of unemployed mothers had $41 \%$ higher odds for exhibiting two or three risk behaviours. Maternal unemployment was significantly associated with having two or three risk behaviours only among boys and not among girls.

\section{Discussion and conclusions}

This study investigated the relationship between children's PA risk behaviours, childhood overweight and maternal characteristics.

\section{Physical activity risk behaviours and childhood overweight}

We found two key PA risk behaviours associated with overweight in children. First, children who actively played outside less than one hour a day had higher odds for overweight in comparison to their peers who spent longer time playing outdoors. This result is concurrent with the results from previous studies showing that, when playing outside, children are usually physically active (Stone \& Faulkner, 2014). When spending one hour or longer every day in active outdoor play, children get the opportunity to meet the WHO PA recommendations which serves as a protective factor for overweight/ obesity (Tremblay, et al., 2015). Secondly, children who spent more than two hours per day in front of a screen had higher odds for overweight confirming that screen time activities present a substantial risk factor for the development of overweight/obesity in children (Allen \& Vella, 2015). Nowadays, the multitude of ways in which screens and media are being used is broadening at an increasingly high pace and it is almost impossible to expect that the children will not be using them more frequently. Accordingly, it is important to bear in mind that in order to preserve children's health, we need to make sure that they get enough opportunities for regular PA, sufficient sleep, social communications and adequate nutrition (Reid Chassiakos, Radesky, Christakis, Moreno, \& Cross, 2016).

\section{Maternal characteristics and physical activity risk behaviours}

The determined positive association of active free-time outdoor play and a negative impact of prolonged screen time on children's weight status is also vital from the perspective of creating healthy habits in children. In this process, parents, who build the foundation of child's lifestyle habits throughout the early years, should set an example for their children and encourage them to actively spend their free time (Natale, et al., 2014). Traditionally, in Croatia, mothers have a predominant role in child rearing (Leinert Novosel, 2018), for which reason maternal characteristics greatly influence the development of child's habits. In our study, we found that individual PA risk behaviours in children were associated with specific maternal characteristics. Lower maternal education levels were found to be protective for playing outside sufficiently. This confirms previous findings showing a negative association between parental education and playing outside (Loprinzi, Schary, \& Cardinal, 2013). It is possible to hypothesize that children whose mothers have higher levels of education and are employed, more often choose to send their children to sport or dancing clubs rather than let them play outside, a privilege that children of less educated and unemployed mothers with usually lower financial possibilities mostly lack (Quinto Romani, 2011). This argument is supported by our finding that lower maternal education, unemployment and overweight presented lower odds for regularly frequenting a sports or dancing club. Additionally, children of overweight mothers had higher odds for insufficient sleep duration and not frequenting a sports or dancing club regularly. Healthy weight mothers may have a higher awareness of the importance of healthy lifestyles and hence make sure their children get sufficient sleep and PA by attending sports or dancing clubs regularly. Interestingly, screen time was not associated with neither of the studied maternal characteristics.

Furthermore, when addressing examined PA risk behaviours as a cumulative score value, our study found that children with two and three co-existing PA risk behaviours were more likely to be overweight. These findings are in line with a previous study on the same risk behaviours that found children with two to four PA risk behaviours to have the highest odds for obesity (Wijnhoven, et al., 2015).

When examining the relationship between maternal characteristics and children's PA risk behaviour scores, we found that lower levels of maternal education were associated with higher odds for one, two or three PA risk behaviours, especially among girls. This finding is in line with previous research showing that maternal education is inversely associated with high inactivity patterns (Gordon-Larsen, McMurray, \& Popkin, 2000). In this case, higher education may be associated with a higher health literacy enabling more educated mothers to use their knowledge about healthy life- 
styles and apply it to their children (Hernandez \& Napierala, 2014). Furthermore, we found that children, especially sons of unemployed mothers had higher odds for having a PA risk score of two or three. This is in contradiction with a previous study that explored the mechanism behind the relationship between maternal employment and children's obesity and found that employed women spend significantly less time playing and playing sports with their children, possibly triggering risk PA behaviours (Cawley \& Liu, 2012). This finding could be explained by the burden brought by unemployment where mothers cannot financially afford to enrol their children in organized sports activities and are too preoccupied by their financial struggle to consciously support their children in healthy lifestyles. In relation to maternal overweight, we found that children of overweight mothers had higher odds for a PA risk score of two, which is a determined risk factor for overweight. Other studies also confirmed the relationship between a high maternal BMI and low levels of children's PA, as well as more sedentary time (Sijtsma, Sauer, \& Corpeleijn, 2015).

\section{Limitations of the study}

The present study is not without limitations. First, the response rate was $79.2 \%$, suggesting that a non-response bias might be at play. However, when implementing a national study using anthropometric measurements, such as this one, the achieved response rate is to be expected and is in line with achieved response rates in other countries using COSI methodology. Second, data on maternal overweight was self-reported suggesting that mothers may have given inaccurate answers. Third, this study did not consider any other information on family's socioeconomic status, such as family income, parental employment, paternal education or family form which could have affected the results. Future research would benefit from involving information on both parents in order to gain a clearer picture of parental characteristics associated with children's PA risk behaviours.

Conclusively, this is the first Croatian national study investigating the associations between PA risk behaviours and overweight in children as well as maternal characteristics and PA risk behaviours in children. The research confirmed association between PA risk behaviours in children and overweight, and maternal characteristics as well. Therefore, maternal characteristics should be taken into consideration when planning and implementing public health policies and interventions directed to the promotion of children's healthy weight and regular PA.

\section{References}

Allen, M.S., \& Vella, S.A. (2015). Screen-based sedentary behaviour and psychosocial well-being in childhood: Cross-sectional and longitudinal associations. Mental Health and Physical Activity, 9, 41-47. doi: 10.1016/j. mhpa.2015.10.002

Ariza, C., Sánchez-Martínez, F., Serral, G., Valmayor, S., Juárez, O., Pasarín, M. I., ..., \& López, M.J. (2019). The incidence of obesity, assessed as adiposity, is reduced after 1 year in primary schoolchildren by the POIBA intervention. The Journal of Nutrition, 149(2), 258-269. doi: 10.1093/jn/nxy259

Aubert, S., Barnes, J.D., Abdeta, C., Abi Nader, P., Adeniyi, A.F., Aguilar-Farias, N., ..., \& Tremblay, M.S. (2018). Global Matrix 3.0 Physical Activity Report card grades for children and youth: Results and analysis from 49 countries. Journal of Physical Activity and Health, 15(s2), S251-S273. doi: 10.1123/jpah.2018-0472

Brown, J.E., Broom, D.H., Nicholson, J.M., \& Bittman, M. (2010). Do working mothers raise couch potato kids? Maternal employment and children's lifestyle behaviours and weight in early childhood. Social Science and Medicine, 70(11), 1816-1824. doi: 10.1016/j.socscimed.2010.01.040

Cawley, J., \& Liu, F. (2012). Maternal employment and childhood obesity: A search for mechanisms in time use data. Economics and Human Biology, 10(4), 352-364. doi: 10.1016/j.ehb.2012.04.009

Chastin, S.F.M., Palarea-Albaladejo, J., Dontje, M.L., \& Skelton, D.A. (2015). Combined effects of time spent in physical activity, sedentary behaviors and sleep on obesity and cardio-metabolic health markers: A novel compositional data analysis approach. PLOS ONE, 10(10), e0139984. doi: 10.1371/journal.pone.0139984

Ekelund, U., Hildebrand, M., \& Collings, P.J. (2014). Physical activity, sedentary time and adiposity during the first two decades of life. Proceedings of the Nutrition Society, 73(2), 319-329. doi: 10.1017/S0029665114000019

European Union. (2015). Regions in the European Union - Nomenclature of territorial units for statistics - NUTS 2013/EU-28. Retrieved from https://ec.europa.eu/eurostat/web/products-manuals-and-guidelines/-/KS-GQ-14006 on April 1, 2020.

Ferreira, I., van der Horst, K., Wendel-Vos, W., Kremers, S., van Lenthe, F.J., \& Brug, J. (2007). Environmental correlates of physical activity in youth ? A review and update. Obesity Reviews, 8(2), 129-154. doi: 10.1111/j.1467789X.2006.00264.X

Gordon-Larsen, P., McMurray, R.G., \& Popkin, B.M. (2000). Determinants of adolescent physical activity and inactivity patterns. PEDIATRICS, 105(6), e83-e83. doi: 10.1542/peds.105.6.e83 
Guinhouya, B.C., Samouda, H., Zitouni, D., Vilhelm, C., \& Hubert, H. (2011). Evidence of the influence of physical activity on the metabolic syndrome and/or on insulin resistance in pediatric populations: A systematic review. International Journal of Pediatric Obesity, 6(5-6), 361-388. doi: 10.3109/17477166.2011.605896

Gunnarsdottir, T., Rogers, R.J., Jakicic, J.M., \& Hill, J.O. (2014). Leisure-time physical activity and obesity. In G.A. Bray \& C. Bouchard (Eds.), Handbook of Obesity (Vol. 1, $3^{\text {rd }}$ ed.; pp. 385-395). Boca Raton, FL: CRC Press. doi: $10.1201 /$ b16473-40

Hernandez, D.J., \& Napierala, J.S. (2014). Mother's education and children's outcomes: How dual-generation programs offer increased opportunities for America's families. Disparities among America's Children. No. 2. New York, NY: Foundation for Child Development.

Leinert Novosel, S. (2018). Društveni položaj žena u Republici Hrvatskoj: žena i obitelj (1999. - 2016.). [Social Status of Women in Croatia: Woman and Family 1999-2016. In Croatian.] Politička Misao, 55(1), 53-73. doi: 10.20901/ pm.55.1.04

Loprinzi, P.D., Schary, D.P., \& Cardinal, B.J. (2013). Adherence to active play and electronic media guidelines in preschool children: Gender and parental education considerations. Maternal and Child Health Journal, 17(1), 56-61. doi: 10.1007/s10995-012-0952-8

Martin, M.A., Lippert, A.M., Chandler, K.D., \& Lemmon, M. (2018). Does mothers' employment affect adolescents' weight and activity levels? Improving our empirical estimates. SSM - Population Health, 4, 291-300. doi: 10.1016/j.ssmph.2018.03.003

Masoumi, H.E. (2017). Active transport to school and children's body weight: A systematic review. TeMA-Journal of Land Use, Mobility and environment, 10(1), 95-110. doi: 10.6092/1970-9870/4088

Mendis, S., Armstrong, T., Bettcher, D., Branca, F., Lauer, J., Mace, C., ..., \& Stevens, G. (2014). Global status report on noncommunicable diseases 2014. Geneve: World Health Organization.

Musić Milanović, S., Lang Morović, M., \& Markelić, M. (2018). Childhood Obesity Surveillance Initiative, Croatia 2015/2016 (CroCOSI). Zagreb: Croatian Institute of Public Health.

Natale, R.A., Messiah, S.E., Asfour, L., Uhlhorn, S.B., Delamater, A., \& Arheart, K.L. (2014). Role modeling as an early childhood obesity prevention strategy. Journal of Developmental and Behavioral Pediatrics, 35(6), 378-387. doi: 10.1097/DBP.0000000000000074

Pahkala, K., Heinonen, O.J., Lagström, H., Hakala, P., Sillanmäki, L., Kaitosaari, T., ..., \& Simell, O. (2010). Parental and childhood overweight in sedentary and active adolescents. Scandinavian Journal of Medicine and Science in Sports, 20(1), 74-82. doi: 10.1111/j.1600-0838.2008.00870.x

Péneau, S., Salanave, B., Rolland-Cachera, M.-F., Hercberg, S., \& Castetbon, K. (2011). Correlates of sedentary behavior in 7 to 9 -year-old French children are dependent on maternal weight status. International Journal of Obesity, 35(7), 907-915. doi: 10.1038/ijo.2011.104

Quinto Romani, A. (2011). Children's weight and participation in organized sports. Scandinavian Journal of Public Health, 39(7), 687-695. doi: 10.1177/1403494811421058

Reid Chassiakos, Y., Radesky, J., Christakis, D., Moreno, M.A., \& Cross, C. (2016). Children and adolescents and digital media. Pediatrics, 138(5), e20162593. doi: 10.1542/peds.2016-2593

Sherar, L.B., Griffin, T.P., Ekelund, U., Cooper, A.R., Esliger, D.W., van Sluijs, E.M F., ..., \& Page, A.S. (2016). Association between maternal education and objectively measured physical activity and sedentary time in adolescents. Journal of Epidemiology and Community Health, 70(6), 541-548. doi: 10.1136/jech-2015-205763

Sherburne Hawkins, S., Cole, T.J., Law, C., Dezateux, C., Peckham, C., Bedford, H., ..., \& Rich, C. (2009). Examining the relationship between maternal employment and health behaviours in 5-year-old British children. Journal of Epidemiology and Community Health, 63(12), 999-1004. doi: 10.1136/jech.2008.084590

Sijtsma, A., Sauer, P.J.J., \& Corpeleijn, E. (2015). Parental correlations of physical activity and body mass index in young children - the GECKO Drenthe cohort. International Journal of Behavioral Nutrition and Physical Activity, 12(1), Article no. 132. doi: 10.1186/s12966-015-0295-0

Stodden, D.F., Langendorfer, S.J., Goodway, J.D., Roberton, M.A., Rudisill, M.E., Garcia, C., \& Garcia, L.E. (2008). A developmental perspective on the role of motor skill competence in physical activity: An emergent relationship. Quest, 60(2), 290-306. doi: 10.1080/00336297.2008.10483582

Stone, M.R., \& Faulkner, G.E.J. (2014). Outdoor play in children: Associations with objectively-measured physical activity, sedentary behavior and weight status. Preventive Medicine, 65, 122-127. doi: 10.1016/j.ypmed.2014.05.008

Taheri, S. (2006). The link between short sleep duration and obesity: We should recommend more sleep to prevent obesity. Archives of Disease in Childhood, 91(11), 881-884. doi: 10.1136/adc.2005.093013

Tremblay, M.S., Carson, V., Chaput, J.-P., Connor Gorber, S., Dinh, T., Duggan, M., ..., \& Zehr, L. (2016). Canadian 24-hour movement guidelines for children and youth: An integration of physical activity, sedentary behaviour, and sleep. Applied Physiology, Nutrition, and Metabolism, 41(6; Suppl. 3), S311-S327. doi: 10.1139/apnm-20160151

Tremblay, M., Gray, C., Babcock, S., Barnes, J., Bradstreet, C., Carr, D., ..., \& Brussoni, M. (2015). Position Statement on Active Outdoor Play. International Journal of Environmental Research and Public Health, 12(6), 6475-6505. doi: 10.3390/ijerph120606475 
U.S. Department of Health and Human Services. (2018). 2018 Physical activity guidelines advisory committee scientific report. Retrieved from https://health.gov/sites/default/files/2019-09/PAG_Advisory_Committee_Report.pdf on April 1, 2020.

Welk, G.J., Wood, K., \& Morss, G. (2003). Parental influences on physical activity in children: An exploration of potential mechanisms. Pediatric Exercise Science, 15(1), 19-33. doi: 10.1123/pes.15.1.19

Whiting, S., Buoncristiano, M., Gelius, P., Abu-Omar, K., Pattinson, M., Mendes, R., ..., \& Breda, J. (2020). Physical activity, screen time and sleep duration of children aged 6-9 years in 25 countries: An analysis within the WHO European Childhood Obesity Surveillance Initiative - COSI 2015/2017. Obesity Facts, 14(1), 32-44.

Wijnhoven, T.M.A., van Raaij, J.M., Yngve, A., Sjöberg, A., Kunešová, M., Duleva, V., ..., \& Breda, J. (2015). WHO European Childhood Obesity Surveillance Initiative: Health-risk behaviours on nutrition and physical activity in 6-9-year-old schoolchildren. Public Health Nutrition, 18(17), 3108-3124. doi: 10.1017/S1368980015001937

WHO - World Health Organization. (2013). WHO: Growth reference data for 5-19 years. Retrieved from Who Child Growth Standards website: http://www.who.int/growthref/en/www.who.int/growthref/en/ 1/2 on April 1, 2020.

WHO - World Health Organization. (2016). Childhood Obesity Surveillance Initiative (COSI), Protocol (October 2016). Retrieved from http://www.euro.who.int/_data/assets/pdf_file/0018/333900/COSI-protocol-en.pdf on April 1, 2020.

WHO - World Health Organization. (2018). COSI Fact Sheet. Highlights 2015/2017. Retrieved from http://www.euro. who.int/_data/assets/pdf_file/0006/372426/WH14_COSI_factsheets_v2.pdf?ua=1 on April 1, 2020.

WHO - World Health Organization. (2020). WHO guidelines on physical activity and sedentary behaviour. Geneva: WHO.

Submitted: April 2, 2020

Accepted: November 1, 2021

Published Online First: December 6, 2021

Correspondence to:

Helena Križan, mag.paed.soc

Health Promotion Division

Croatian Institute of Public Health

Rockefellerova 7, Zagreb, 10000 Croatia

Tel: +38514863 358

E-mail: helena.krizan@hzjz.hr 